\title{
SPASMOPHILIA WITH ESPECIAL REFERENCE TO FAMILIAL REACTIONS AND REPEATED ABSENCES *
}

\author{
JULIUS PARKER SEDGWICK, M.D.
}

MINNEAPOLIS

New light has been thrown on the subject of convulsions and allied conditions in childhood by the study of the electrical reactions. This work was begun and carried out for years by Escherich. ${ }^{1}$ General convulsions in children, laryngospasm, spasmodic apnea, tetany and similar phenomena have been shown to be but manifestations of an underlying hyperexcitability of the peripheral nervous system, with a tendency to tonic and clonic spasms, the so-called spasmophilic diathesis.

Mechanically the hyperirritability can be shown by tapping over the seventh nerve along its course in the cheek, with a resulting contraction of the muscles around the mouth. Tapping over the upper branches of the same nerve may produce a similar contraction about the eye. The first is known as Chvostek's and the second as Weiss' phenomenon. Constriction of the arm in this condition at times brings on the tetany position of the hand-Trousseau's phenomenon. The Chvostek and Weiss phenomena are therefore indicative of spasmophilia. The Trosseau phenomenon is pathognomonic.

More important, however, because they can be more accurately measured, are the electric reactions. In the normal child, with the Stinzing electrode applied over the peroneal nerve, no cathodal or anodal opening contraction is produced with less than five milliamperes of galvanic current. Charts 1 to 6 , as given by von Pirquet, ${ }^{2}$ show the normal reactions as well as those of hyperexcitabiliy.

The first column, $\mathrm{C} \mathrm{CC}$, represents cathodal closing contraction, the others in order, A C C, anodal closing contraction, A O C, anodal opening contraction and the fourth, $\mathrm{C} \mathrm{O} \mathrm{C}$, cathodal opening contraction. The amount of current necessary to produce the contractions is shown by the height of the blocking indicated by the number of milliamperes on the left of the standard specimen blank chart above charts 1 to 6 .

* Read in the Section on Diseases of Children of the American Medical Association, at the Sixty-Fourth Annual Session, held at Minneapolis, June, 1913.

1. Escherich, Theodor: Die Tetanie, Hölder, Vienna and Leipsic, 1909

2. Cited from Escherich: Die Tetanie. 
The study of the electrical reactions has shown that there may be a latent spasmophilic condition or an active state with such manifestations as have been mentioned above. Ibrahim states that at certain times of the year 30 per cent. or more of the children show spasmophilia latent or active. The importance of the recognition of this latent condition, in order that the proper prophylactic treatment for the prevention of convulsions may be instituted, is evident.

Characteristic pathologic anatomic changes have not been shown in the nervous system of spasmophilies. Escherich, basing his conclusions on the work of Yanase and Erdheim, considered the condition due to changes in the parathyroids. Later, negative findings by various investigators have, however, thrown doubt on this hypothesis.

The studies of Quest and others on the brains of infants indicate a low calcium content in these cases. Mac Callum and others have demon-

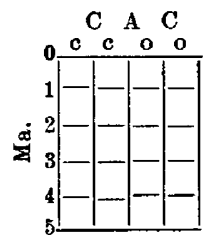

${ }_{\text {Normal }}$ B

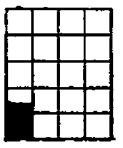

1

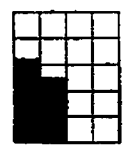

2
$\mathrm{C}_{\text {Anodal }} \mathrm{D}$

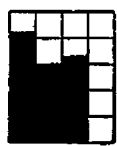

4
$\mathbf{E}_{\text {Cathodal }}$ F

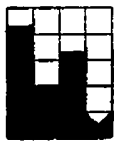

5

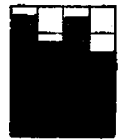

6

Charts 1.2.-Normal reactions given by von Pirquet.

Charts 3.6.-Hyperexcitability reactions given by von Pirquet.

strated that the calcium of the brains of animals suffering with tetany parathyreopriva is low. Cohn and Cooke have on the other hand, had somewhat contradictory results. Herman Schwarz ${ }^{3}$ suggests that these conflicting results may mean that it is the calcium-sodium ratio which is of most importance, as in the case of this character in which the calcium content was high the sodium content was also high, making in one of Aschenheim's cases a quotient of forty-six instead of the normal one from nineteen to twenty-six. Although Gerstenberger did not succeed in obtaining improvement in these cases by the oral administration of calcium lactate and Grulee's metabolism work gives little or no con-

3. Schwarz, Herman, and Bass, Murray H.: The Calcium Metabolism in Infantile Tetany, with Report of a Case, Am. Jour. Dis. Child., January, 1912, p. 15. 
firmation of this hypothesis, it is very probable that there is some relationship between spasmophilia and the calcium metabolism.

Manifestations of spasmophilia are much more common in the late winter and early spring months. Breast-fed children are rarely affected. According to Finkelstein ${ }^{4}$ the whey of cow's milk is an exciting factor. Infectious diseases or alimentary disturbances may change a latent spasmophilia into an active condition with convulsions. Rickets and spasmophilia frequently occur together.

It has long been recognized that this condition is hereditary or familial. The literature, however, shows few records of familial electric reactions. Schiffer ${ }^{5}$ reports one family in which the mother and one child of 15 years gave normal electric reactions, and two of the children showed hyperelectric excitability.

Toyofuku ${ }^{8}$ took the electric reactions of four newly born puppies whose mother had been subjected to the removal of the thyroid and parathyroid glands. All four showed marked tetany reactions. The mother showed definite signs of tetany and heightened electric reactions after the birth of the puppies. He considers the condition as a lactation tetany. He believes that a tetany or tendency to tetany may be transmitted through the milk. Without knowledge of this work on dogs I have examined the electric reactions of the mothers of the somewhat rare cases of spasmophilia in breast-fed children which have come to my attention, and have found the irritability of the mothers almost uniformly high.

Case 1.-John D. was 51/2 months old when first seen by me, March, 1911. He was still at the breast. His aunt had had convulsions as a child and she is now mentally deficient. The mother stated that she took four quarts of milk and cream daily during her pregnancy and at the time of the examination her diet was almost wholly made up of milk and cream. The infant was brought to me because it had had repeated convulsions. The child was markedly rachitic with pronounced craniotabes. His electrical reactions were spasmophilic as shown in Chart 7 (April 13) and Chart 8 (July 18).

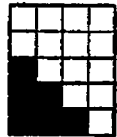

7

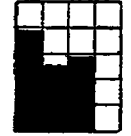

8

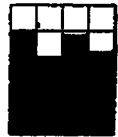

9

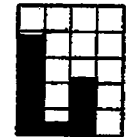

10

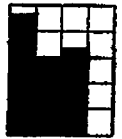

11

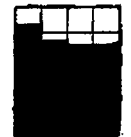

12

Charts 7 and 8.-John D., Case 1, April 13 and April 18, 1911. Chart 9.-The nursing mother of John D., Case 1, July 25, 1911. Charts 10 and 11.-Anne B., Case 2, Nov. 22 and Nov, 26, 1912. Chart 12. - The nursing mother of Anne B., Case 2, Nov. 22, 1912.

4. Finkelstein: Lehrbuch der Säuglingskrankheiten, Berlin, 1905, Part 1, p. 248 .

5. Schiffer: Ueber familiare chronische Tetanie, Jahrb. f. Kinderh., 1911, lxxiii, 601 .

6. Toyofuku, T.: Beitrag zum experimentellen Studium der Lactationstetanie, Jikazasshi M. 130, 1911; Cited from Ztschr. f. Kinderh., 1911, i. R., p. 592. 
The markedly spasmophilic reactions of the nursing mother of John D. are given in Chart 9 (July 25).

CAse 2.-Anne B. was 5 months old and at the breast at the time of her first examination. She had rickets with marked craniotabes and gave the reaction shown in Chart 10 (November 22) and Chart 11 (November 26).

The nursing mother gave a marked Chvostek phenomenon and her electrical reactions were striking, as shown in Chart 12 (November 22).

CASE 3.-William $R$. was 9 months old and at the breast when he came under my care, Nov. 14, 1912. He had had repeated convulsions from his fourth month. He still has convulsions and there is a decided mental injury. His reactions are shown in Chart 13 (November 15) and Chart 14 (December 15).

The nursing mother's reactions show marked hyperexcitability, Chart 15 (November 15), and Chart 16 (November 20).

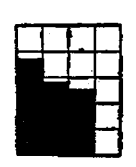

13

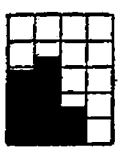

14

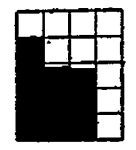

15

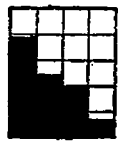

16

Charts 13 and 14.-William R., Case 3, Nov. 15 and Dec. 15, 1912.

Charts 15 and 16. The nursing mother of William R., Case 3, Nov. 15 and Nov. 20, 1912 .

CASE 4.-E. G., a girl of 3 months, and at the breast, had convulsions, but no demonstrable hyperelectrical excitability, Chart 17 (September 4). She had been given chloral hydrate.

The nursing mother, however, gave evidence of hyperexcitability on the same day. Chart 18 (September 4).

CASE 5.-George $L$. died at the age of 1 year with broncho-pneumonia and beginning tuberculous meningitis following pertussis. There was marked tetany for some time before death. Unfortunately, the child's reactions could not be taken, but the reactions of the mother, who was nursing him, are shown in Chart 19 (May 29).

CASE 6.--Irma E. was under my care at the age of 6 months with pyelocystitis. Although her electrical reactions were not taken, she had marked tetany of both hands. The nursing mother's reactions are given in Chart 20 (October 29).

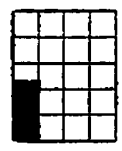

17

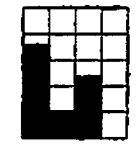

18

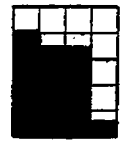

19

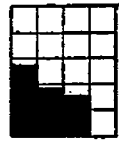

20

Chart 17.-E. G., Case 4, Sept. 4, 1912. Chart 18.-The nursing mother of E. G., Case 4, Sept. 4, 1912.

Chart 19.-The nursing mother of George L., Case 5, May 29, 1912.

Chart 20.-The nursing mother of Irma E., Case 6, October 29, 1912.

In but two cases of spasmophilia which I have seen in infants at the breast, the mothers have not shown very marked electric excitability. One of these children showed marked carpopedal spasm, but was getting 
other food as it was in its third year. The other was also older, 2 years and 3 months, and also had marked tetany.

To recapitulate: In all of the cases of infants, 1 year or less of age at the breast whom I have examined and found spasmophilic, the nursing mothers have shown definitely heightened electric excitability.

The electric reactions of other members of the families of spasmophiliacs often bear out the frequently made assertion that the condition is hereditary or familial.

CASE 7.-In the family of Baby J. D., as shown by Chart 21 (August 1), the mother, brother and aunt have heightened electric reactions, as well as Chvostek phenomena, Chart 22 (July 25), Chart 23 (November 21) and Chart 24 (October 22). The aunt had had convulsions as a child and is now mentally deficient. An uncle had had convulsions during his first year. The grandmother presented a marked Chvostek phenomenon, but without heightened electrical excitability (Chart 25).

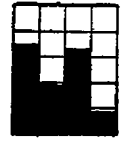

21

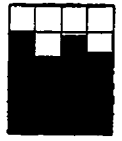

22

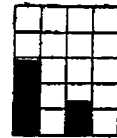

23

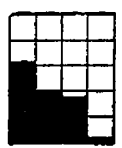

24

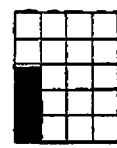

25

Chart 21.-John D., Case 7, Aug. 1, 1911. Chart 22.-The mother of John D., Case 7, July 25, 1911. Chart 23.-The brother of John D., Case 7, Nov. 21, 1912. Chart 24.-The aunt of John D., Case 7, Oct. 22, 1912. Chart 25.-The grandmother of John D., Case 7.

CASE 8.-Baby R. R., with convulsions and a marked Chvostek phenomenon, gave spasmophilic reactions. (Chart 26, February 13). The mother's reactions are shown in Chart 27 (December 26).

CASE 9.-Baby Q. T. had convulsions and marked spasmophilic reactions. (Chart 28, December 28).

The mother had had convulsions as a child and the high reactions shown in Chart 29 (December 28).

CAsE 10.-Theo. McC. has had convulsions, and his mother gave similar reactions. (Charts 30 and 31 , March 21.)

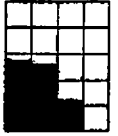

26

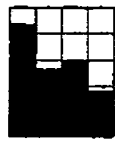

27

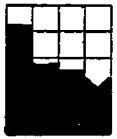

28

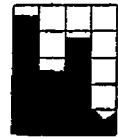

29

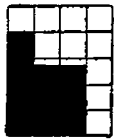

30

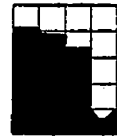

31

Chart 26.-Baby R. R., Case 8, Feb. 13, 1913. Chart 27.-The mother of Baby R. R., Case 8, Dec. 26, 1912.

Chart 28.-Baby Q. T., Case 9, Dec. 28, 1912. Chart 29.-The mother of Baby Q. T., Case 9, Dec. 28, 1912.

Chart 30.-Theo. McC., Case 10, March 21, 1913. Chart 31.-The mother of Theo. McC., Case 10, March 21, 1913.

CASE 11.-Baby B. J. gave spasmophilic reactions (Chart 32, July 27), the mother did not, but the father did (Charts 33 and 34). All three showed the Chvostek phenomenon, the father's being especially marked. 
CASE 12.-This is also true of Virginia J. (Chart 35, April 3), her mother (Chart 36, March 1), and father (Chart 37, November 1).

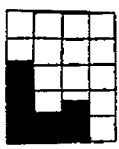

32

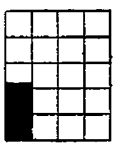

33

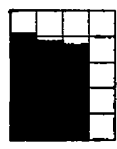

34

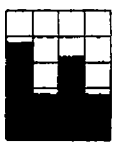

35

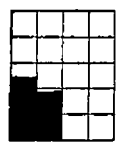

36

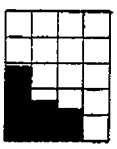

37

Chart 32.-Baby B. J., Case 11, July 27, 1912. Chart 33.-Mrs. J., the mother, Case 11. Chart 34.-Mr. J., the father, Case 11.

Chart 35.-Virginia J., Case 12, April 3, 1913. Chart 36.-The mother of Virginia J., Case 12, March 1, 1913. Chart 37.-The father of Virginia J., Case 12, Nov. 1, 1912.

CASE 3.-Baby W. R., had active spasmophilia for months with reactions shown in Chart 38 (November 20 ).

Mrs. R., his mother showed marked hyperexcitability (Chart 39, November 20). His father (Chart 40 , November 21), as well as his parents, the grandmother and grandfather (Charts 41 and 42, November 20), showed less marked evidences of hyperexcitability.

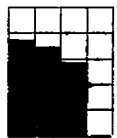

38

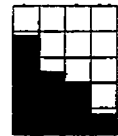

39

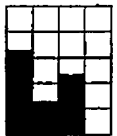

40

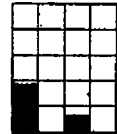

41

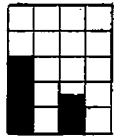

42

Chart 38.-William R., Case 3, Nov. 20, 1912. Chart 39.-The mother of William R., Case 3, Nov. 20, 1912. Chart 40.-The father of William R., Case 3, Nov. 21, 1912. Chart 4l.-The paternal grandmother of William R., Case 3, Nov. 20, 1912. Chart 42.-The paternal grandfather, Case 3, Nov. $20,1912$.

CAsE 13.-The B. family, in which the father had had convulsions as a child, consisted of nine children, eight of whom had had convulsions in childhood. The three who could be examined gave the heightened reactions shown in Charts 43-45, together with the Chvostek phenomenon. The last reaction is interesting as it is that of the only son who did not have convulsions, showing a latent spasmophilia.

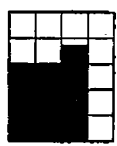

43

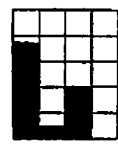

44

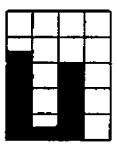

45

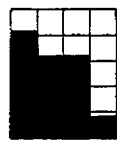

46

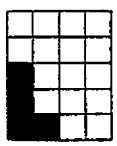

47

Chart 43.-Mr. B., Case 13. Chart 44.-The son of Mr. B., Case 13. Chart 45.-The only son of Mr. B. who did not have convulsions.

Charts 46 and 47.-S. S., Case 14, Aug. 3 and Sept. 12, 1912.

Further repetition from my records would only consume time. The cases in which one or both parents of spasmophilic children do not give like reactions are exceptional.

We are indebted to Friedmann for the recognition of the character of the repeated non-epileptic "absences" in children, which so resemble 
petit mal. He considers that they bear no relation to epilepsy and apparently have nothing to do with hysteria. They are characterized by the following peculiarities: They begin in apparently well children from the fourth to the seventh year, usually suddenly after some excitement, such as fear or operation. They consist of short, light disturbances of consciousness without convulsions and without falling. They come on at first in a great number of attacks (6 to 10 to 100 a day and occasionally at night). The course of the disease is tedious, usually being from seven to eight years. There may be also long remissions. They have no disturbing influence on the mental or bodily development of the child. This is a chief argument against their relation to epilepsy from which they, moreover, differ, in that the occurrence of convulsive attacks is almost never observed (fast völlige Ausbleiben). They are also to be distinguished from epilepsy by the history. Against their hysteric nature, the uniformity of the attacks, in spite of continuance for years as well as the lack of other symptoms which would make one suspicious of hysteria, may be cited. The "repeated absences" present a good prognosis in that they appear to clear up before puberty even without treatment. So far as the systematic placing is concerned, they may be related to the narcolepsy of Gelineaus and the other somewhat half-understood "neurotic absences" of adults. It seems that they appear on the foundation of a spasmophilic diathesis as, in the three cases which have been so far recently tested electrically, the increase of electric excitability and cathodal opening contraction with less than 5 milliamperes has been observed (two of these observations were made by Mann).

CAsE 14.-S. S., aged 7, seen first Aug. 3, 1912. She has been under my olservation during the past year and illustrates the above condition as described by Friedmann. Her father and mother are living and well. She was a fullterm child and birth was normal. She has had no acute infections and although she lived two years in the Philippines she did not contract malaria. Her father was in the habit of giving her as many as six drinks of whisky a day, and the mother thinks that the "spells" which she has had have followed the abuse of alcohol.

Two years ago she began to have attacks which were diagnosed as petit mal. She usually had from one to fifty of them and has had as high as one hundred a day. The attacks were first noticed at the table. She would stop eating and stare off into space. During the attacks she does not answer when spoken to. The first attacks lasted only a few seconds each, but at the present time they are sometimes much longer. She was examined by two very competent men, who said it was epilepsy. They gave her bromids and advised country life and all the milk and eggs she could take. She was taken to the country and given the medicine prescribed, without improvement. While in the country she would sink to the ground when the attacks came on and at times had as many as one hundred "spells" a day.

The physical examination showed a fairly well-nourished, gracile child of dark complexion. She made quick movements which were not of choreiform character. The general physical examination showed nothing of importance. 
The electrical reactions, which were markedly spasmophilic, are shown in Chart 46 (August 3), and Chart 47 (September 12).

On August 3, during the examination in the office, she looked off into space and the pupils became somewhat dilated and the expression blank. The attack lasted about ten seconds, after which she immediately became the active, alert, apparently normal ehild she was before. She was sitting on the edge of a table from which she did not fall and seemed to have no difficulty in keeping her position. She said nothing during the attack, although she had been talking on and off before. During the attack she seemed to notice that her dress was unbuttoned in the back, although the expression was still vacant. There was no Chvostek phenomenon. The patellar reflexes were very marked. The Achilles tendon reflexes were present and marked.

She was put on a carbohydrate diet without milk or meat and given phosphorus in cod-liver oil, but no sedatives.

The decrease in the number of attacks can be readily seen from the curve extending from Aug. 4 to Sept. 25, 1912. (Chart 48.) On September 12 she

August

September

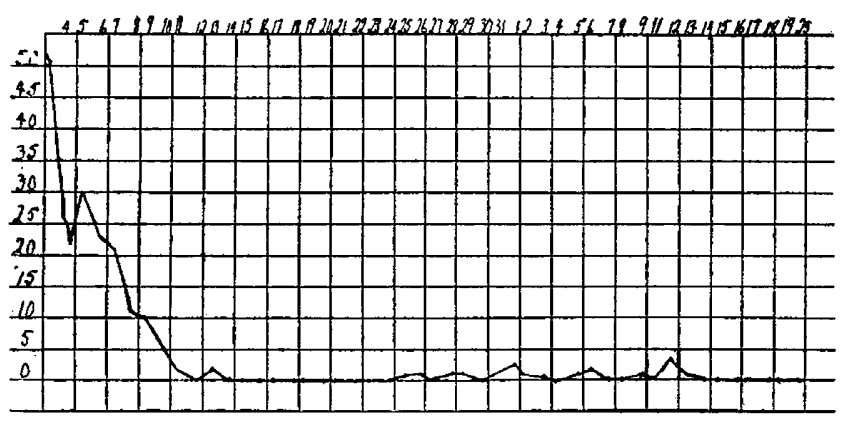

Chart 48.-Decrease in epileptic attacks. Case 14, Aug. 4 to Sept. 25, 1912.

left Minneapolis, but continued with the milk-and-meat free diet, and the mother reported from St. Joseph, Missouri, on Oct. 26, 1912, that she was having about one attack a week and that very slight. The treatment was continued. On Nov. 26, 1912, she reported from Cheyenne, Wyoming, that the child had had no attacks since October 26. The treatment was ordered continued. On Dec. 20, 1912, she reported from Tacoma, Washington, that the child had not had any more attacks and was doing well. During the spring of 1913 she had a recurrence, but she was in the West and there was no opportunity to take her reactions. As the spasmophilic season of the year passed over she improved.

CASE 15.-Another case, but with some motor symptoms, which is still under observation with slight improvement, is that of Edith N., aged 11. The mother's brother is said to have had epilepsy at the age of 4 or 5 years, but as he recovered and is now well he may have had spasmophilia. This child began to have attacks two years ago. She was sitting on a table during examination. Without any warning the eyelide dropped, the eyeballs showed nystagmus and turned upward slightly. As she leaned forward there seemed to be an attempt to right herself as one who falls asleep in a chair. The attack lasted from three to five seconds. She seemed normal immediately afterward, but could give no proper description of the attack. She has from twenty to thirty-five of these daily. The electrical reactions may be seen in Chart 49 (January 10). If this case is epilepsy, there is spasmophilia present also, as shown by the electrical reactions. 
It is possible that the following case, which shows both petit mallike attacks and convulsions, may be a link between "repeated absences" and the spasmophilic convulsions. In my opinion, such electric reactions and the Chvostek sign warrant a better prognosis than in epilepsy proper.

CAsE 16.-Joe D. was a well-nourished boy of 9 years when first seen in September, 1912. His testicles have not descended. His infant brother was seen by me in typical spasmophilic convulsions and now shows marked anodal hyperirritability. One year before the first examination Joe $D$. had two or three attacks a day for one week. In these attacks he fell and was rigid and unconscious. The attacks then ceased until five days before this examination. He has had from two to six attacks daily since. His mother says that they manifest themselves at this time as a blank expression which comes over his face for a few seconds. He answers questions at this time but has no recollection of them afterward. During the physical examination he had just such a manifestation as his mother described. He appeared perfectly normal immediately afterward. His electric reactions are shown in Chart 50 (September 12).

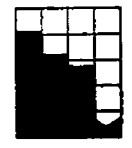

49

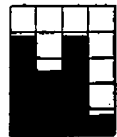

$\overline{\mathbf{5} 0}$

Chart 49.-Edith N., Case 15, Jan. 10, 1913.

Chart 50.-Joe D., Case 16, Sept. 12, 1912.

The Chvostek phenomenon was pronounced. These attacks continued, with some which showed clonic convulsions, until October 10. From that time until the present, June 4, 1913, he has had no more seizures. The history with the electrical reactions and Chvostek phenomenon warrant the diagnosis of spasmophilia.

The diagnosis of spasmophilia rests on the electric reactions, convulsions, tetany, laryngospasm, spasmodic apnea, together with the Trousseau, Chvostek and allied phenomena. Not only have we here an aid in the differentiation of these convulsions from those of major epilepsy, but certain cases of petit mal may belong under this heading.

Although death does occur in the general convulsions and in laryngospasm, under proper treatment the prognosis, so far as life is concerned, is usually favorable. Thiemich and Mann found, however, that about one-third of these cases show later evidences of injury to the mentality.

The accepted treatment consists in the withdrawal of cow's milk with the substitution of breast-milk when possible, or carbohydrates in the shape of gruels, and the administration of cod-liver oil and phosphorus. Sedatives, such as chloral hydrate, may be necessary in the active stages. The calcium therapy is not as yet generally used. The recent studies in this subject will require rewriting of the chapters on convulsions to be found in most of the texts on pediatrics.

Syndicate Building. 